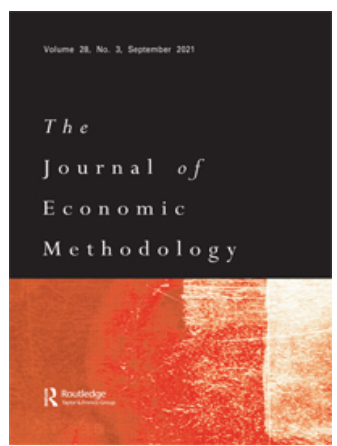

Journal of Economic Methodology

\title{
Dispersed information and the non-neutrality of money: fifty years after Lucas, 1972
}

\section{Pierrick Clerc \& Rodolphe Dos Santos Ferreira}

To cite this article: Pierrick Clerc \& Rodolphe Dos Santos Ferreira (2022): Dispersed information and the non-neutrality of money: fifty years after Lucas, 1972, Journal of Economic Methodology, DOI: $10.1080 / 1350178 X .2022 .2033811$

To link to this article: https://doi.org/10.1080/1350178X.2022.2033811

\section{Published online: 01 Feb 2022.}

Submit your article to this journal

Q View related articles $\sqsubset$

View Crossmark data $\asymp$ 


\title{
Dispersed information and the non-neutrality of money: fifty years after Lucas, 1972
}

\author{
Pierrick Clerc (D) ${ }^{a}$ and Rodolphe Dos Santos Ferreira (iD ${ }^{b}$

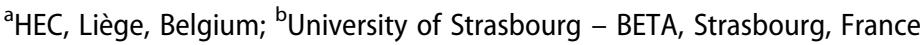

\begin{abstract}
This paper highlights the renewed interest in Lucas's explanation of the non-neutrality of money put forward in his 1972 article - explanation based on information dispersion and signal extraction problems - by an increasing part of the literature investigating the transmission mechanism of monetary policy shocks. We review the main contributions to this renewal, and illustrate the relationship between this work and Lucas's own model. We also show that some of the assumptions made by this line of research have been questioned by subsequent developments on the same track, thereby challenging its ability to produce large amounts of monetary non-neutrality and calling for further research.
\end{abstract}

\section{ARTICLE HISTORY}

Received 13 September 2021 Accepted 21 January 2022

\section{KEYWORDS}

Robert Lucas; monetary nonneutrality; rational inattention; history of macroeconomics

JEL Classification B22; D80; E30; E40

\section{Introduction}

Lucas's, 1972 seminal paper has been mostly associated with the introduction of the rational expectations hypothesis in macroeconomics, after its initial formulation by John Muth in the context of industrial economics. ${ }^{1}$ Contrary to John Muth, who explicitly states that the objective of [his] paper is to outline a theory of expectations' (Muth, 1961, p. 316), Lucas does not refer to rational expectations as the object of his paper, but rather as a self-imposed constraint conforming with 'the discipline imposed by classical economic theory'. ${ }^{2}$ Indeed, his proclaimed objective is to show that 'a systematic relation between the rate of change in nominal prices and the level of real output' - the Phillips curve - can be 'derived within a framework from which all forms of "money illusion" are rigorously excluded: all prices are market clearing, all agents behave optimally in light of their objectives and expectations, and expectations are formed optimally' (Lucas, 1972, p. 103; our emphasis).

If this is so, Lucas's intended contribution does not lie in using rational expectations as such but in proposing a strategy that makes the absence of money illusion compatible with the non-neutrality of money as expressed by the Phillips curve. This strategy consists in revisiting Phelps (1969) islands parable of dispersed information in separate markets on the basis of now rational (instead of adaptive) expectations. We thus end up with 'three distinguishing characteristics' of Lucas's model:

prices and quantities at each point in time are determined in competitive equilibrium; the expectations of agents are rational, given the information available to them; information is imperfect, not only in the sense that the future is unknown, but also in the sense that no agent is perfectly informed as to the current state of the economy. (Lucas, 1975, p. 1113; emphasis in the original)

Here, the two first characteristics are just the reminder of the two neoclassical postulates of rationality and (competitive) equilibrium already recalled in the beginning of the 1972 paper. It is the third 
characteristic that is the distinctive trait with respect to the neoclassical core. This characteristic is the imperfection, more precisely the dispersion, of information, not about an uncertain future but rather about the 'current state of the economy'. As we shall see, for any agent, forming expectations rationally translates in this context into extracting optimally from the noisy available observations a signal about the current state. And the signal extraction would ideally (but only ideally) allow to separate real idiosyncratic shocks from pure nominal systemic shocks, so that the absence of money illusion would then materialize indeed in the neutrality of money.

This kind of signal extraction problem, central to the islands model where information is not only imperfect but also heterogeneous among different agents, curiously disappears in the works of the immediate successors or contesters of Lucas's achievement. In the next decisive paper for the installation of the New Classical macroeconomics, a signal extraction problem subsists, but 'a representative infinitely-lived household is assumed' (Kydland \& Prescott, 1982, p. 1345), which leads to homogeneous information. And on the opposite side, New Keynesian economists neglect Lucas's informational strategy to focus on the challenge of the neoclassical equilibrium discipline, by invoking price stickiness, sluggish expectation formation, or else equilibrium multiplicity as a source of coordination failures.

There was nevertheless a place left for the continuation of Lucas's central argument. Lucas 'tried to abstract from all sources of persistence of fluctuations, in order to focus on the nature of the initial disturbances' (Lucas, 1972, p. 105 n. 4; emphasis in the original), by assuming in particular that these disturbances become public information one period only after their occurrence. As a consequence, the non-neutrality of money he proved to be compatible with the neoclassical postulates, in particular with rational expectations, appeared as a pure transient phenomenon, in spite of empirical evidence for lasting effects of monetary disturbances.

In this paper, we show that the last two decades have witnessed a resurgence of Lucas's central argument. Since the early 2000s, indeed, a growing part of the literature investigating the real effects of monetary shocks (or, in other words, the transmission mechanism of monetary policy) has proposed models in which the non-neutrality of money in the short run stems from dispersed information and signal extraction problems. We review the main contributions to this line of research, and illustrate the relationship between this work and Lucas's own model. ${ }^{3}$ We notably stress that, while initially promising, subsequent developments have cast some doubts on the ability of these models to deliver large amounts of monetary non-neutrality.

The resurgence of Lucas's explanation of the non-neutrality of money has been initiated by Michael Woodford in his pioneering contribution on imperfect common knowledge. Woodford (2003a) argues that two important departures from Lucas's model would make Lucas's explanation consistent with persistent real effects from monetary shocks. First, these shocks no longer become public information one period after their occurrence. This may be not because the relevant information is unavailable but because agents have only limited capacity for processing information an idea initially formulated by Sims $(1998,2003)$ - and, consequently, pay limited attention to monetary shocks. Second, Woodford moves from perfect to imperfect competition and supposes that, as a result of strategic complementarities in price setting, the optimal price for any firm to charge depends upon the average level of prices set by the competitors. The rational expectations hypothesis must now be applied not only to the estimate by each agent of the current money supply, but also to the infinite hierarchy of higher-order expectations (the estimates of the average estimate of other agents, of the average estimate of that average estimate, and so on). These two alternative assumptions will be at the core of all the subsequent contributions to this strand of the literature.

The framework proposed by Woodford has actually three main limitations. First, and most importantly, the degree of inattention to relevant available information due to the limited information-processing capacity is purely exogenous. This means that a crucial source of persistence is, in fact, only postulated. In an influential article, Maćkowiak and Wiederholt (2009) address this issue and make inattention rational, since resulting from an optimizing decision under the constraint of a given capacity to process information. They introduce large idiosyncratic shocks into Woodford's model, 
and show that the much smaller size of aggregate nominal shocks induces firms to pay very limited attention to these latter. Strong and persistent monetary non-neutralities therefore arise endogenously.

Secondly, the response of higher-order expectations to monetary shocks is simply a monotone transformation of the response of first-order expectations (i.e. the expectations about the shock itself). This means that higher-order expectations do not play an independent role in the persistent response of real variables. Angeletos and $\mathrm{La}^{\prime} \mathrm{O}$ (2009) argue that the tight connection between firstand higher-order expectations in Woodford's model relates to the structure of information assumed in this model. They consider an alternative information structure which no longer implies such a tight connection, and illustrate the key role played by higher-order expectations in the emergence of persistent non-neutralities.

Thirdly, the demand side of the economy is not micro-founded. This stands in sharp contrast with most other models used to study the transmission mechanism of monetary policy - in particular those belonging to the dynamic stochastic general equilibrium (DSGE) paradigm. Maćkowiak and Wiederholt (2015) build a fully-fledged DSGE model where both firms and households are subject to rational inattention. They point out the critical importance of households' rational inattention in the ability of the model to replicate the hump-shaped response of aggregate output to monetary shocks documented in the VAR literature.

At the same time, some authors have suggested that these improvements - and especially that brought about by Maćkowiak and Wiederholt in their 2009 paper - involve assumptions that would considerably amplify the size and persistence of the real effects from monetary shocks. For instance, it is assumed in the rational inattention framework that firms can fully separate information about idiosyncratic shocks from information about aggregate nominal shocks. Hellwig and Venkateswaran (2009) stress that this assumption would not be innocuous: when firms are not able to make such a clear separation, they raise their prices much more aggressively after a monetary expansion. A substantial reduction in the amount of monetary non-neutrality ensues. Similarly, in this framework firms set the price of only one good. However, the menu cost literature has made it clear that the number of different goods priced by individual firms has important implications for the amount of monetary non-neutrality. Pasten and Schoenle (2016) embed multi-product firms into the model of Maćkowiak and Wiederholt (2009) and show that pricing many goods (each subject to specific shocks) would lead firms to pay more attention to aggregate nominal shocks. They find that the amount of monetary non-neutrality when firms price two goods is cut by three with respect to the single-good case, and money becomes almost neutral when firms price eight goods or more. At the same time, the results of both Hellwig and Venkateswaran (2009) and Pasten and Schoenle (2016) are partly driven by particular aspects of their respective set-ups. Hence, more research seems required in order to have clear ideas about the ability of rational inattention to induce large and persistent real effects from monetary shocks.

The rest of the paper is organized as follows. Section 2 discusses the methodological dimension of Lucas's, 1972 paper. Section 3 proposes a simplified version of Lucas's model, focusing on the signal extraction problem. This simplified version will enable us to make explicit the connection between Lucas's model and the work exposed in the subsequent sections. Section 4 presents the pioneering contribution of Woodford. Section 5 turns to the improvements suggested to overcome the limitations of Woodford's model, while Section 6 deals with some issues raised by these improvements. Section 7 concludes.

\section{A brief methodological prolegomenon to Lucas's model}

To recall what has been stressed in the introduction, the objective of Lucas (1972) was to show that the Phillips curve can be derived within a framework in which 'all prices are market clearing, all agents behave optimally in light of their objectives and expectations, and expectations are formed optimally' (p. 103). Lucas's framework is thus based on the neoclassical methodological 
discipline, which imposes 'the two postulates (a) that markets be assumed to clear, and (b) that agents be assumed to act in their own self-interest' (Lucas \& Sargent, 1978, p. 58; cf. our fn. 2).

Adherence to the postulate of market clearing confronts Lucas's methodological approach to the incipient general disequilibrium modeling initiated in 1971 by Robert Barro and Herschel Grossman, but stillborn in America. In the latter approach, price rigidity results in rationing of the long market side, the consequences of which are fully and correctly taken into account by optimizing agents, so that 'disequilibrium' is actually a misnomer. The important point in the present context is however that referring to market clearing prices is not enough to characterize Lucas's methodological position. One must add (as Lucas explicitly did in 1975) that those prices are formed in competitive markets. In other words, Lucas adopts the stronger form of the neoclassical discipline, which assumes perfect competition. We know since Cournot that this is a limit case, by no means essential to the neoclassical framework and abandoned by Woodford, in a critical methodological step, when he reconsidered Lucas's model. By assuming instead imperfect competition between price setting agents, he introduced strategic complementarities that make those agents anticipate, as in Keynes's beauty contest, not only the fundamentals ruling clearing prices but also, maybe principally, the average price decisions expected to be made by the competitors.

The second postulate of the neoclassical discipline is what came to be called the micro-foundations of the macroeconomic model: the economy behavior results, by aggregation, from the actions of rational individuals, pursuing their objectives under correctly perceived constraints, hence in equilibrium. Explicit micro-foundations were absent from much of postwar macroeconomics, but had already been put in the foreground by the contributions to the volume Phelps et al. (1970), among which one co-authored by Lucas and the Phelps introduction, which is one of Lucas's references. The novelty in Lucas (1972) is the emphasis on the optimal formation of expectations, which are not only correct (as they would be under perfect foresight or else in the limit of a converging adaptive process), but assumed to be optimally extracted from the individual's available information. Also, this information is partly private, heterogeneous among individuals, a decisive trait of Lucas's island model contrasting with both Muth (1961) and Kydland and Prescott (1982).

\section{A simplified version of Lucas's islands model}

Let us consider an economy composed of a large number of separate goods markets ('islands'), each featuring perfect competition. In any period, the demand for goods expressed on a given island is the product of an aggregate component (common to all islands) and an island-specific component. Specifically, by expressing all variables in logarithms and denoting the level of nominal spending on island $i$ in period $t$ by $q_{t}(i)$, the level of aggregate nominal spending by $q_{t}$ and the level of nominal spending specific to island $i$ by $\varepsilon_{i, t}$, we have:

$$
q_{t}(i)=q_{t}+\varepsilon_{i, t} .
$$

Aggregate demand follows a random walk with drift $\mu$ :

$$
q_{t}=p_{t}+y_{t}=q_{t-1}+\mu+\varepsilon_{q, t} .
$$

where $p_{t}$ denotes the price level, $y_{t}$ the level of aggregate output, and $\varepsilon_{q, t}$ the shocks on aggregate nominal spending. These shocks follow a Gaussian white noise process with variance $\sigma_{q}^{2}$. We assume that monetary shocks are the single source of aggregate demand disturbances, so that $\varepsilon_{q, t}$ actually denotes monetary shocks. Island-specific demand, instead, follows a Gaussian white noise process with variance $\sigma_{i}^{2}$, independent from $\varepsilon_{q, t}$, and independently distributed across islands.

The economy supply side is composed of self-employed workers (hereafter 'firms') dispersed across islands. The supply of goods on island $i$ in period $t, y_{t}(i)$, is such that:

$$
y_{t}(i)-y^{n}=\alpha\left(q_{t}(i)-\mathbb{E}_{i, t} q_{t}\right),
$$

where $y^{n}$ denotes the level of potential (or natural) output common to all islands (and assumed to be 
constant), $\alpha$ a reduced-form parameter (depending, in particular, upon the elasticity of labor supply), and $\mathbb{E}_{i, t}$ the expectations operator conditional upon the information available on island $i$ in period $t$.

In words, Equation (3) says that the level of output on a given island is above potential only when the demand expressed on this island is relatively higher than the demand expressed on the other islands. However, while they can observe the whole demand expressed on their respective islands, firms cannot distinguish between the aggregate and island-specific components. Indeed, because of their dispersed locations, firms cannot observe aggregate variables in real time. Supplying goods thus requires them to form 'expectations' about the current level of aggregate demand.

In order to form expectations about $q_{t}$, firms on island $i$ have two relevant sources of information in period $t$. First, they can observe $q_{t}(i)$ and use this observation to infer the value of $q_{t}$. Hence, observing the demand expressed on their island provides firms with a (noisy) signal about the current level of aggregate demand. The 'signal-to-noise' ratio (measuring how observing $q_{t}(i)$ is informative about $q_{t}$ ) associated with this signal extraction problem is $s_{q}=\sigma_{q}^{2} / \sigma_{i}^{2}$. Secondly, they know the value of $q_{t-1}$. Indeed, monetary shocks occurring in period $t-1$ (and, therefore, the level of aggregate demand in that period) are assumed to become public information at the beginning of period $t$. While knowledge of $q_{t-1}$ is not enough to exactly infer $q_{t}$, it nevertheless allows to determine a 'prior' distribution on $q_{t}$, common to all firms in the economy. Given Equation (2), this distribution is known to be normal, with mean $q_{t-1}+\mu$ and variance $\sigma_{q}^{2}$.

These two sources of information imply that the information set used by firms on island $i$ to form expectations about $q_{t}$ consists of the signal $q_{t}(i)$ and the mean of the prior distribution $q_{t-1}+\mu$. Firms then form expectations through Bayesian updating:

$$
\mathbb{E}_{i, t} q_{t}=\mathbb{E}\left[q_{t} \mid q_{t}(i), q_{t-1}+\mu\right]=\frac{\varsigma_{q}}{1+\varsigma_{q}} q_{t}(i)+\frac{1}{1+s_{q}}\left(q_{t-1}+\mu\right) .
$$

Finally, combining Equations (3) and (4), averaging over $i$ and using Equation (2), gives:

$$
y_{t}-y^{n}=k^{L} \varepsilon_{q, t}
$$

with $k^{L}=\alpha \frac{1}{1+\varsigma_{q}}$.

According to Equation (5), the size of the real effects of monetary shocks critically depends on the value of the signal-to-noise ratio $s_{q}$. When $s_{q}$ is very low, variations in the demand faced by firms are a poorly informative signal about variations in aggregate demand (since, as $\sigma_{i}^{2}$ is much higher than $\sigma_{q}^{2}$, the variations of $q_{t}(i)$ are mainly island-specific). In this case, monetary shocks have a large impact on aggregate output $y_{t}$ since aggregate demand variations are, to a large extent, confused with relative demand variations. By contrast, when $s_{q}$ is very high, variations in the demand faced by firms are a very informative signal about variations in aggregate demand. In this case, monetary shocks have only a small impact on aggregate output (money is nearly neutral) since aggregate demand variations are, to a large extent, correctly identified.

Equation (5) makes also clear that the real effects of monetary shocks are purely transitory: a shock occurring in a given period cannot affect aggregate output beyond that single period. Hence, while monetary shocks can generate large real effects on impact, these effects completely vanish after one period. This implication directly results from the assumption that monetary shocks become public information (which fully dispels any initial confusion between relative and aggregate demand variations) one period after their occurrence.

\section{Reconciling Lucas's explanation of monetary non-neutrality with persistent real effects from monetary shocks}

\subsection{Two major methodological amendments}

A well-known fact about monetary shocks - extensively documented in the classic work of Friedman and Schwartz (1963), and more recently in the VAR literature (notably by Christiano et al. (2005) and 
Altig et al. (2011)) - is that they have highly persistent real effects. Christiano et al. (2005), for instance, find that aggregate output returns to its initial level no sooner than three years after the occurrence of an expansionary monetary shock. Lucas's model is therefore unable to account for a crucial dimension of monetary non-neutrality.

In a paper prepared for a conference held in 2001 in honor of Phelps, Woodford proposes to reconsider what he calls the 'Phelps-Lucas hypothesis', according to which the 'real effects of purely nominal disturbances result from imperfect information about the nature of these disturbances' (Woodford, 2003a, p. 56). He argues that the highly transient effects of monetary shocks on aggregate output in Lucas's model come from two particular assumptions made by Lucas, not from the Phelps-Lucas hypothesis per se. Woodford's aim is to show that once these assumptions are modified, 'it is possible to explain not only real effects of purely nominal disturbances, but real effects that may persist for a substantial period of time'. The Phelps-Lucas hypothesis thus 'deserves more continued interest than is often supposed'.

The first assumption - emphasized in Section 2 - is that firms operate in perfectly competitive markets. Woodford argues that this environment does not completely exploit the informational isolation of the separate decision makers captured by the island parable. Indeed, the only information that matters to those decision makers is then the current value of an exogenous aggregate state variable, whereas an important source of uncertainty is the unknowability of the minds of others. Instead, a monopolistic competition framework featuring strategic complementarities in price setting should be considered. In such an environment, firms find it optimal to set their prices by reacting not only to their own expectations about current aggregate demand, but also (since they are uncertain about the expectations of other firms) to their 'higher-order expectations' - i.e. their expectations about other firms' expectations, their expectations about other firms' expectations about other firms' expectations, and so on. Thus, besides their incapacity to know the current level of aggregate demand, firms do not know either what other firms know about this level. In other words, Woodford's model involves what the theory of games calls imperfect common knowledge. The fact that higher-order expectations matter for the prices that are set is a central aspect of Woodford's strategy to explain persistence of real effects of monetary shocks, because higher-order expectations display even more inertia in response to aggregate demand shocks than firms' own expectations about these shocks. ${ }^{4}$

The second assumption - pointed out in Section 3 - is that monetary shocks become public information after one period. According to Woodford, however, the Gordian knot is not so much that information about these shocks is made available soon after their occurrence, but rather that firms are (implicitly) supposed to be able to fully absorb and process all available information. Woodford, instead, follows a line of argumentation initially developed by Sims (1998, 2003), according to which firms would have limited capacity for processing information. In Woodford's model, firms cannot pay more than limited attention to information about the current state of aggregate demand. Hence, even if information about monetary shocks is immediately published, it takes time for firms to process this information, and to integrate it into their information set.

The two amendments brought by Woodford into Lucas's model may be viewed as a weakening, for the sake of 'realism', of the methodological discipline defining the neoclassical framework: competition becomes less than perfect and the treatment of information by the decision makers ceases to be accomplished instantaneously. ${ }^{5}$ However, we favor the opposite point of view. As already suggested, if we go back to Cournot's installment of the neoclassical paradigm, we find producers who do make expectations about the minds of their competitors and it is only in the limit case of indefinite (rather than 'perfect') competition that making expectations about market variables suffices, since each individual action becomes insignificant with respect to the market outcome. Also, taking information processing as costly in terms of time - a rare resource - means that this processing is treated on the same footing as the production process, in purely classical terms. There is no weakening but rather a deepening of the neoclassical discipline. 


\subsection{Woodford's imperfect common knowledge model}

The main insights of Woodford's model can be formalized as follows. The demand side is summarized by Equation (2), and the economy is only hit by monetary shocks. The supply side is composed of a continuum of firms in monopolistic competition. If there were no information frictions, firm $j$ would set its period $t$ price, $p_{t}^{*}(j)$, according to:

$$
p_{t}^{*}(j)=(1-\xi) p_{t}+\xi\left(q_{t}-y^{n}\right),
$$

where $\xi(0,1)$ denotes a reduced-form parameter measuring the degree of strategic interactions in price setting. ${ }^{6}$

All information about the aggregate state of the economy is publicly available to every firm. However, because of finite information-processing capacity, firms observe aggregate variables only imperfectly. The price actually set by firm $j$ in period $t, p_{t}(j)$, is thus given by:

$$
p_{t}(j)=(1-\xi) \mathbb{E}_{j, t} p_{t}+\xi\left(\mathbb{E}_{j, t} q_{t}-y^{n}\right),
$$

where $\mathbb{E}_{j, t}$ denotes the expectations operator conditional upon the information available to firm $j$ in period $t$.

Firms can solely observe a noisy private signal about current aggregate demand. The signal observed by firm $j$ in period $t$, denoted by $s_{q, t}(j)$, is represented as follows:

$$
s_{q, t}(j)=q_{t}+e_{q, t}(j),
$$

with $e_{q, t}(j)$ following a Gaussian white noise process with variance $\tilde{\sigma}_{q}^{2}$, independent from $\varepsilon_{q, t}$, and independently distributed across firms. The signal-to-noise ratio (measuring how observing $s_{q, t}(j)$ is informative about $q_{t}$ ) associated with this signal extraction problem is $\tilde{s}_{q}=\sigma_{q}^{2} / \tilde{\sigma}_{q}^{2}$. Since firms receive different signals (and ignore the signals received by others), information about current aggregate demand is dispersed.

In addition, firms never know exactly the true value of aggregate demand, even after many periods. As a result, they can only use the history of their private signals up to period $t$ in order to form expectations about $q_{t}$. In the case of firm $j$, we have:

$$
\mathbb{E}_{j, t} q_{t}=\mathbb{E}\left[q_{t} \mid s_{q, t}(j), s_{q, t-1}(j), s_{q, t-2}(j), s_{q, t-3}(j), \ldots\right] .
$$

However, Equation (7) implies that the price set by a given firm also depends on this firm's expectation of the average level of prices charged by the other firms. Since all firms set prices in a similar way, each firm has to form an expectation of the average expectation among the other firms about $q_{t}$, an expectation of the average expectation of that average expectation, and so on. Hence, on top of its own expectation of $q_{t}$, every firm has to form higher-order expectations about $q_{t}$.

Let $\mathbb{E}_{j, t}^{(h)} q_{t}$ denote firm j's expectation of $q_{t}$ of order $h$, and $\overline{\mathbb{E}}_{t}^{(h-1)} q_{t}={ }_{j, t}^{\mathbb{E}}(h-1) q_{t}$ dj the average expectation (among firms) of $q_{t}$ of order $h-1$. Firm $j$ 's expectation of order $h$ is its expectation of the average expectation of order $h-1$, i.e. $\mathbb{E}_{j, t}^{(h)} q_{t}=\mathbb{E}_{j, t}\left[\overline{\mathbb{E}}_{t}^{(h-1)} q_{t}\right]$. Equation (7) can then be rewritten as: ${ }^{7}$

$$
p_{t}(j)=\xi\left[\sum_{h=1}^{\infty}(1-\xi)^{(h-1)} \mathbb{E}_{j, t}^{(h)} q_{t}\right]-\xi y^{n} .
$$

The importance of higher-order expectations for pricing decisions critically depends on the value of $\xi$. When $\xi=1$, there are no strategic interactions in price setting since (according to Equation (7)) the price set by a given firm is independent from the prices set by the other firms. In this case, Equation (10) makes it clear that pricing decisions only depend on firms' own expectations of $q_{t}$ (i.e. on their 'first-order expectations' of $\left.q_{t}\right), E_{j, t} q_{t}$. By contrast, when $\xi<1$, there are strategic complementarities in price setting since it is optimal for a given firm to raise its price when it expects the other firms to raise theirs. In this case - which is the one usually retained in the pricing literature - Equation (10) 
shows that higher-order expectations not only matter for pricing decisions, but also increasingly influence those decisions. ${ }^{8}$ Indeed, the stronger strategic complementarities (i.e. the lower $\xi$ ), the higher the order of expectations firms have to consider, and the larger the weights firms have to attach to expectations of higher orders. Intuitively, this stems from the fact that the stronger the strategic elements between firms, the more important become the expectations held by the other firms in the decisions taken by a given firm.

Moreover, since $\frac{\varsigma_{q}}{1+\tilde{s}_{2}}<1$, it can be shown that expectations of higher order react less strongly to private signals than éxpectations of lower order. For instance, when a positive monetary shock occurs, the resulting rise in the private signal observed by each individual firm induces a rise in third-order expectations which is more sluggish than the rise in second-order expectations, itself more sluggish than the rise in first-order expectations.

These dynamics are illustrated by Figure 1, which displays the responses of first-order $(h=1)$ and higher-order ( $h=2 \ldots 8$ ) expectations to an immediate, permanent unit increase in aggregate demand $(h=0){ }^{9}$ The increasing sluggishness of higher-order expectations reflects the fact that firms are increasingly uncertain about other firms' expectations, since these expectations are formed from information sets that differ from their own.

Finally, applying optimal filtering techniques, averaging the various equations over $j$, and making technical assumptions to ensure the uniqueness of equilibrium, yields:

$y_{t}-y^{n}=k^{W}\left(y_{t-1}-y^{n}+\varepsilon_{q, t}\right)$
with $k^{W}=1-\frac{1}{2}\left\{-\xi \tilde{\varsigma}_{q}+\left[\left(\xi \tilde{s}_{q}\right)^{2}+4 \xi \tilde{s}_{q}\right] \frac{1}{2}\right\}$. equations reveals the main similarities and differences between the two models.

Let us first consider the main similarity. According to Equation (11), monetary shocks have a larger impact on aggregate output when the signal-to-noise ratio $\tilde{s}_{q}$ is lower (since $k^{W}$ increases as $\tilde{s}_{q}$ falls). As a result, exactly as in Lucas's model (where $k^{L}$ increases as $s_{q}$ falls), the size of monetary non-neutrality is all the more important that the signal observed by firms is poorly informative about the actual state of aggregate demand. Recall that in the context of Lucas's model, this implication stems from the fact that with a poorly informative signal monetary shocks are, to a large extent, confused with island-specific shocks. In Woodford's model, a poorly informative signal means that firms

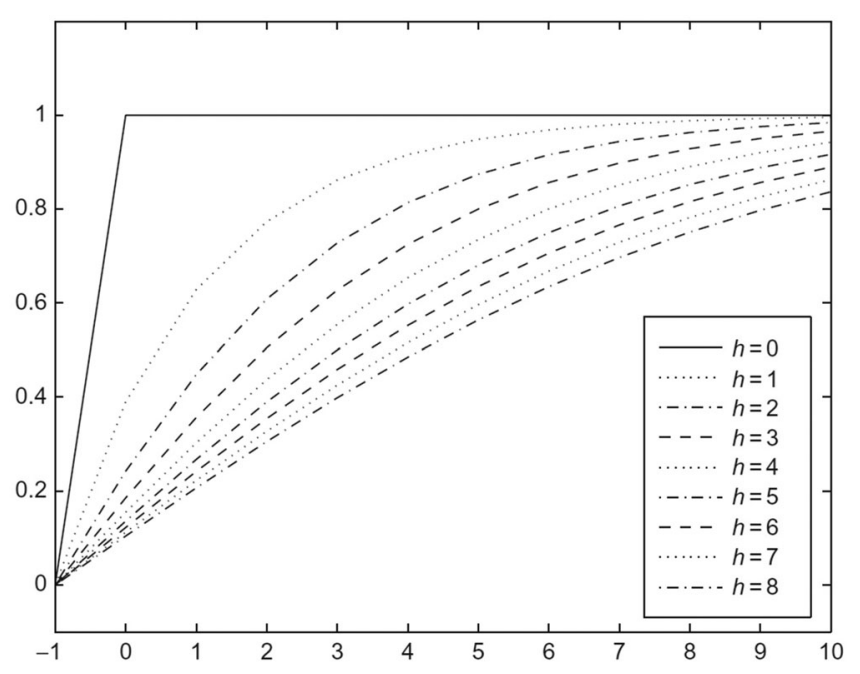

Figure 1. Dynamics of first- and higher-order expectations in Woodford (2003a). 
pay only limited attention to aggregate variables (i.e. they process only a limited amount of available information about those variables). They thus fail to adjust their prices in response to monetary shocks, leading to large fluctuations in aggregate output.

Let us now consider the main difference. In Equation (11), $y_{t}$ depends on both $\varepsilon_{q, t}$ and $y_{t-1}$. As a result, contrary to what happens in Lucas's model (where $y_{t}$ depends solely on $\varepsilon_{q, t}$ ), aggregate output responds not only to current realizations of monetary shocks, but also - and crucially - to past realizations of these shocks. This means that in Woodford's model, monetary shocks have persistent real effects.

The quantitative importance of this persistence is driven by $k^{W}$. This coefficient is made of two components, each encapsulating a key mechanism at work. The first component is the signal-tonoise ratio $\tilde{s}_{q}$, illustrating once again the role played by the 'informativeness' of the signal observed: when this signal is poorly informative, it takes a very long time for firms to learn that a monetary shock has occurred (even if the information on this occurrence is available from the start), and to adjust their prices accordingly. ${ }^{10}$ Hence, aggregate output displays persistent deviations from its potential level. The second component is the parameter $\xi$, illustrating the role played by strategic complementarities in price setting. When these complementarities are strong (i.e. when $\xi$ is low), firms need to form expectations of very high orders, and to attach large weights to them in their pricing decisions. At the same time, expectations of higher orders react more sluggishly to information than expectations of lower orders. Strong strategic complementarities therefore slow down the response of prices to monetary shocks, leading to persistent deviations of aggregate output from potential.

\section{Overcoming the limitations of Woodford's model}

\subsection{Making inattention rational}

We have just seen that in Woodford's model, a poorly informative private signal - embodied in a low value of the signal-to-noise ratio $\tilde{s}_{q}$ - is a central mechanism through which monetary shocks produce persistent real effects. A poorly informative signal is meant to represent the limited attention firms pay to the current state of aggregate demand when they have limited capacity for processing information. In this model, however, $\tilde{s}_{q}$ is a free parameter whose value can be arbitrarily selected by the modeler. ${ }^{11}$ This means that retaining a low value for $\tilde{\varsigma}_{q}$ amounts, in fact, to imposing that firms pay only limited attention to the state of aggregate demand. Hence, an important source of persistent monetary non-neutralities in Woodford's model turns out to be nothing more than postulated. The treatment of information by the decision makers is viewed as a time consuming process but no possibility is open for them to modulate this process, in particular by paying more or less attention to the state of aggregate as compared to idiosyncratic demand shocks.

The main contribution of Maćkowiak and Wiederholt (2009) is to explain the persistent real effects of monetary shocks by the rational decision of firms to pay limited attention to the state of aggregate demand. In the framework set out in that paper, firms allocate their attention to track both idiosyncratic and aggregate demand shocks. Maćkowiak and Wiederholt show that the allocation chosen by firms depends on the relative impact of these shocks on the prices firms would set absent information frictions. In this context, the signal-to-noise ratio $\tilde{s}_{q}$ is no longer a free parameter: it is a variable chosen by firms as a function of the structural parameters driving the volatility of shocks and the responses of firms' frictionless optimal prices. For realistic values of these parameters, the resulting $\tilde{s}_{q}$ is found to be very low, which means that it is actually optimal for firms to pay very limited attention to information about aggregate demand shocks. This rational inattention with respect to the state of aggregate demand implies that firms adjust very sluggishly their prices in response to monetary shocks, inducing large and persistent fluctuations in aggregate output.

The framework proposed by Maćkowiak and Wiederholt is basically the same as Woodford's. There are, however, three important differences. First, the price that would be set absent information 
frictions also depends on idiosyncratic (cost or demand) conditions. Firm j's frictionless optimal price in period $t$ becomes:

$$
p_{t}^{*}(j)=(1-\xi) p_{t}+\xi\left(q_{t}-y^{n}\right)+\varepsilon_{z, t}(j),
$$

where $\varepsilon_{z, t}(j)$ denotes an idiosyncratic state variable reflecting conditions specific to firm $j$. Firmspecific conditions follow a Gaussian white noise process with variance $\sigma_{z}^{2}$, independent from $\varepsilon_{q, t}$, and independently distributed across firms.

Secondly, the flow of information that firms can effectively process in a given period is now explicitly introduced. This flow, denoted by $\kappa$, reflects firms' limited capacity for processing information (the lower firms' capacity, the lower $\kappa$ ). Moreover, firms can allocate this information flow - i.e. their attention - to track both idiosyncratic and aggregate demand shocks. The flow of information regarding idiosyncratic shocks is denoted by $\kappa_{z}$, while the flow of information regarding aggregate demand shocks is denoted by $\kappa_{q}$. Firms choose the values of $\kappa_{q}$ and $\kappa_{z}$ so as to maximize their expected profits, under the constraint: ${ }^{12}$

$$
\kappa=\kappa_{q}+\kappa_{z} .
$$

As in Woodford's model, information processing limitations prevent firms from observing the precise values of aggregate variables. In particular, firms solely observe a noisy private signal about current aggregate demand. Firm $j$ 's signal about aggregate demand in period $t$ is still denoted by $s_{q, t}(j)$, and still given by Equation (8). In addition, Maćkowiak and Wiederholt assume that information processing limitations also prevent firms from observing the precise values of idiosyncratic variables: firms solely observe a separate noisy private signal about their current idiosyncratic conditions. This signal is modeled in the same fashion as the signal about aggregate demand. Hence, firm j's signal about its own conditions in period $t$, denoted by $s_{z, t}(j)$, is:

$$
s_{z, t}(j)=\varepsilon_{z, t}(j)+e_{z, t}(j),
$$

with $e_{z, t}(j)$ following a Gaussian white noise process with variance $\tilde{\sigma}_{z}^{2}$, independent from $\varepsilon_{z, t}(j)$, and independently distributed across firms. The signal-to-noise ratio (measuring how observing $s_{z, t}(j)$ is informative about $\left.\varepsilon_{z, t}(j)\right)$ associated with this signal extraction problem is $\tilde{\boldsymbol{s}}_{z}=\sigma_{z}^{2} / \tilde{\sigma}_{z}^{2}$. Maćkowiak and Wiederholt's model consequently involves two signal extraction problems.

Thirdly, the information structure is now endogenous. Firms, indeed, can choose the precision of the signals received and, consequently, the value of the signal-to-noise ratios. The precision of the signals depends on firms' attention: the more firms pay attention to a particular type of shocks, the less noisy the associated signal. For instance, the more firms pay attention to aggregate demand shocks (i.e. the higher $\kappa_{q}$ ), the more precise is the signal $s_{q, t}(j)$ (i.e. the lower is $\tilde{\sigma}_{q}^{2}$ ). A more precise signal, in turn, implies a higher signal-to-noise ratio. Therefore:

$$
\tilde{\varsigma}_{q}^{\prime}\left(\kappa_{q}\right)>0 \text { and } \tilde{\varsigma}_{z}^{\prime}\left(\kappa_{z}\right)>0 .
$$

While more complicated to derive analytically, the resulting dynamics of aggregate output are actually very similar to those induced by Woodford's model, and can thus be approximated by Equation (11). This means that, exactly as in that model, monetary shocks generate real effects whose persistence is determined by two mechanisms - respectively encapsulated by $\xi$ and $\tilde{s}_{q}$. In Maćkowiak and Wiederholt's model, however, $\tilde{s}_{q}$ is no longer a free parameter: it is a variable whose value results from the amount of attention firms find it optimal to pay to aggregate demand shocks. Hence, the persistence produced by this model crucially depends on how firms allocate their attention between idiosyncratic and aggregate demand shocks.

Firms' allocation of attention is driven by the relative impact of idiosyncratic and aggregate demand shocks on frictionless optimal prices. This relative impact is, in turn, essentially determined by two factors. The first factor is the relative volatility of aggregate-demand and idiosyncratic shocks, i.e. $\sigma_{q}^{2} / \sigma_{z}^{2}$. This is intuitive: if, for instance, aggregate demand shocks are more volatile than 
idiosyncratic shocks (i.e. if $\sigma_{q}^{2} / \sigma_{z}^{2}>1$ ), aggregate demand shocks will represent a relatively more important source of fluctuations for frictionless optimal prices, creating an incentive for firms to track these shocks with more accuracy. The second factor is the degree of strategic interactions in price setting, i.e. $\xi$. Let us assume that $\sigma_{q}^{2} / \sigma_{z}^{2}>1$, so that firms allocate most of their attention to track aggregate demand shocks. In this case, firms quickly adjust their prices in response to these shocks, since they are quite aware of their occurrence. As a result, the price level displays large fluctuations in response to aggregate demand shocks. If there are strong strategic complementarities (i.e. if $\xi$ is low), it can be seen from Equation (12) that there will be an important feedback effect for firm $j$ : the large movements in the price level imply that firm $j$ 's frictionless optimal price will react even more to aggregate demand shocks. Firm $j$ 's incentive to allocate most of its attention to this type of shocks is therefore reinforced. Hence, strategic complementarities in price setting result in strategic complementarities in attention allocation: when $\xi$ is low, it is optimal for firms to allocate more attention to the shocks for which the other firms allocate most of their attention.

Maćkowiak and Wiederholt argue that, empirically, aggregate demand shocks are much less volatile than idiosyncratic shocks (whose large size is necessary to replicate the large average size of price changes observed in the micro-price data). This means that the actual value of $\sigma_{q}^{2} / \sigma_{z}^{2}$ is much lower than one, suggesting that firms would have a strong incentive to allocate most of their attention to track idiosyncratic shocks. Maćkowiak and Wiederholt also recall that, in the literature on price setting, $\xi$ is usually set between 0.1 and 0.2 . This large degree of strategic complementarities in price setting would entail a large degree of strategic complementarities in attention allocation, reinforcing firms' incentive to allocate attention mostly to idiosyncratic shocks. Under their baseline calibration, Maćkowiak and Wiederholt find that firms choose to allocate $96 \%$ of their attention to idiosyncratic shocks and, consequently, only $4 \%$ to aggregate demand shocks (i.e. $\kappa_{q}^{*}=0.04 \kappa$ ). Since the signal-to-noise ratio $\tilde{s}_{q}$ positively depends on the attention paid to aggregate demand shocks, and since the fluctuations in aggregate output generated by monetary shocks are all the more persistent that $\tilde{s}_{q}$ is low, the very limited attention firms rationally choose to pay to aggregate demand shocks induces highly persistent monetary non-neutralities.

Two remarks are in order. First, as in Woodford's model, strategic complementarities in price setting play a role in the emergence of persistent monetary non-neutralities through the mechanism (described in the previous section) involving higher-order expectations. Contrary to Woodford's model, however, these complementarities also play a role through the strategic complementarities in attention allocation that they induce. Secondly, as in Lucas's model, monetary shocks have a larger impact on aggregate output when firm-specific (island-specific in Lucas's model) shocks are more volatile than aggregate demand shocks, i.e. when $\sigma_{q}^{2} / \sigma_{z}^{2}\left(\sigma_{q}^{2} / \sigma_{i}^{2}\right.$ in Lucas's model) is low. In Lucas's model, this happens to be the case because a low $\sigma_{q}^{2} / \sigma_{i}^{2}$ directly translates into a low signal-to-noise ratio $s_{q}$. In the model of Maćkowiak and Wiederholt, a low $\sigma_{q}^{2} / \sigma_{z}^{2}$ makes it rational for firms to pay only limited attention to aggregate demand shocks, which, in turn, implies a low signal-to-noise ratio $\tilde{s}_{q}$.

\subsection{Providing higher-order expectations with an independent role}

In Woodford's model, the dynamics of higher-order expectations are tightly tied to the dynamics of first-order expectations. Indeed, it can be seen from Figure 1 that the response of higher-order expectations to monetary shocks is actually a monotone transformation of the response of firstorder expectations. Since the rate of convergence of first-order expectations is driven by the signal-to-noise ratio $\tilde{s}_{q}$, this means that the (lower) rate of convergence of higher-order expectations is also driven by $\tilde{s}_{q}$. In particular, if $\tilde{s}_{q}$ is very large, higher-order expectations will converge very quickly to the actual level of aggregate demand, and the real effects of monetary shocks will be highly transient. The tight connection between first- and higher-order expectations therefore precludes any independent role for the latter in the production of persistent monetary non-neutralities. 
Angeletos and $\mathrm{La}^{\prime} \mathrm{O}$ (2009) argue that higher-order expectations can have an independent role to play once it is recognized that the tight connection between first- and higher-order expectations is not a general result, but rather an implication of the structure of information assumed in Woodford's model. To illustrate this point, they consider a variant of Woodford's model in which each firm, while receiving an unbiased private signal (and understanding that its own signal is unbiased) about current aggregate demand, believes that the signals received by all other firms are biased. ${ }^{13}$ Specifically, firm $j$ in period $t$ receives the signal $s_{q, t}(j)$ represented above (and rewritten here for convenience) by Equation (8):

$$
s_{q, t}(j)=q_{t}+e_{q, t}(j),
$$

with $e_{q, t}(j)$ following an independent Gaussian white noise process with variance $\tilde{\sigma}_{q}^{2}$. At the same time, this firm believes that all other firms receive the same kind of signal, but with a noise $e_{q, t}(m)$ following an independent Gaussian process with mean $\delta_{t}$ and variance $\tilde{\sigma}_{q}^{2}$. The mean $\delta_{t}$ is the bias that firm $j$ believes to be present in the private signals received by the other firms. Moreover, Angeletos and La'O assume that $\delta_{t}$ is negatively correlated with aggregate demand shocks and follows an autoregressive process given by:

$$
\delta_{t}=-\chi \varepsilon_{q, t}+\rho \delta_{t-1}
$$

where $\chi(0,1)$ denotes a parameter that controls the correlation of the perceived bias with aggregate demand shocks, and $\rho(0,1)$.

Angeletos and $\mathrm{La}^{\prime} \mathrm{O}$ then show that even though this alternative information structure does not affect first-order expectations, it does affect higher-order expectations. In particular, high values for $\chi$ and $\rho$ induce each firm to strongly believe that the expectations of others will be less sensitive to aggregate demand shocks.

To understand the implications of this alternative information structure, Angeletos and La'O take the extreme case for which the signal-to-noise ratio $\tilde{s}_{q}$ tends to infinity, meaning that every firm is (nearly) perfectly informed about aggregate demand shocks. Under the information structure of Woodford's model, this assumption implies that monetary shocks have no real effects: both firstand higher-order expectations instantly converge to the true value of aggregate demand, and firms immediately adjust their prices one-to-one with monetary shocks. Under the information structure proposed by Angeletos and La'O, instead, monetary shocks do have real effects. To see this, suppose that a positive monetary shock occurs. Given that $\tilde{s}_{q}$ tends to infinity, the first-order expectations of all firms immediately jump to the actual value of aggregate demand - exactly as in Woodford's model. According to Equation (16), however, the positive value of $\varepsilon_{q, t}$ now entails a fall in the perceived bias $\delta_{t}$. This means that each firm, while (nearly) perfectly aware that a positive shock has occurred, believes that the other firms are much less aware (and even not aware at all if $\chi$ is equal to one) of this occurrence. As a result, each firm raises its higher-order expectations only slowly and gradually, and this adjustment will be all the more sluggish as $\chi$ and $\rho$ tend to one. The response of higher-order expectations is thus largely disconnected from the response of first-order expectations. In this context, the response of prices displays substantial inertia, inducing a strong and persistent increase in aggregate output. Hence, higher-order expectations play an independent, and important, role in the emergence of persistent monetary non-neutralities.

\subsection{Considering households' behavior}

In Woodford's model, but also in Maćkowiak and Wiederholt's, the demand side of the economy is not micro-founded. Aggregate demand is simply assumed to follow an exogenous process (controlled by the monetary authority). This is justified by the technical difficulties involved in solving these models, and by the assumption that the source of monetary non-neutrality stems from the supply side of the economy. However, this practice stands in sharp contrast with most other 
models currently used to investigate the real effects from monetary shocks. In particular, the optimizing decisions of every agent are systematically derived in the models belonging to the DSGE paradigm - in accordance with the 'equilibrium discipline' advocated by Lucas.

Maćkowiak and Wiederholt (2015) build a fully-fledged DSGE model in which households, on top of firms, are subject to rational inattention. In this setup, both firms and households have to allocate their limited attention to track three types of disturbances: monetary shocks, aggregate technology shocks, and firm-specific productivity shocks. Every agent in the economy has the opportunity to increase its overall amount of attention, which comes at a constant cost (in terms of time) - the 'marginal cost of attention'. Households have three main decisions to take each period: how much to consume (the intertemporal consumption decision, which depends on the real interest rate), which goods to consume (the consumption mix decision, which depends on the relative prices of goods), and which wage to set.

The most important implication of this extended model is its ability to replicate the hump-shaped response of aggregate output to monetary shocks - a well-established fact from the VAR literature. ${ }^{14}$ Maćkowiak and Wiederholt stress the critical role played by households' rational inattention in this result. Indeed, it is shown that if households had full information about monetary shocks, they would immediately adjust their consumption path in response to variations in the real interest rate. The monotonic response of aggregate consumption would turn into a monotonic, rather than humpshaped, response of aggregate output.

Maćkowiak and Wiederholt point out that, under rational inattention, households (like firms) choose to allocate most of their attention to track firm-specific productivity shocks. This is because these shocks are sizable, inducing large variations in the relative prices of goods. Since goods relative prices are the key determinant in the consumption mix decision, households find it important to be aware of their fluctuations. By contrast, aggregate shocks are much smaller, implying only small variations in the real interest rate. As a result of the small amount of attention allocated to track aggregate shocks, it takes a lot of time for households to learn about the realization of monetary shocks. Being largely uninformed about the occurrence of these latter, households fail to immediately adjust their consumption path in response to the (unnoticed) variations of the real interest rate. After a negative monetary shock, for example, consumption declines only marginally on impact. Households then reduce consumption as they gradually learn about the shock - the peak response occurring three quarters after the shock hit the economy. The resulting humpshaped pattern of aggregate consumption turns into a hump-shaped pattern of aggregate output. Maćkowiak and Wiederholt further show that while this response of consumption causes utility losses with respect to the response that would happen if households had full information about monetary shocks, these losses are insignificant. Households have therefore no incentive to pay more attention to monetary shocks, even if the marginal cost of attention is small.

\section{The role of informational separability and single-good firms assumptions for monetary non-neutrality}

\subsection{Informational separability}

We have seen that in the model set out in Maćkowiak and Wiederholt (2009), each firm receives two separate signals: one about current idiosyncratic conditions, the other about current aggregate demand. This means that firms are able to fully separate information about idiosyncratic conditions from information about aggregate demand. At first sight, even though its accuracy can be questioned, this assumption seems innocuous. Hellwig and Venkateswaran (2009), however, show that this is not the case. They stress that if the signals received do not enable firms to clearly separate information about idiosyncratic conditions from information about aggregate demand, the amount of monetary non-neutrality collapses. 
To illustrate this point, Hellwig and Venkateswaran first consider a simple case in which each firm observes only a single signal encompassing both the current states of aggregate demand and idiosyncratic conditions. Suppose that firm $j$ 's frictionless optimal price is given by the following equation:

$$
p_{t}^{*}(j)=(1-\xi) p_{t}+\xi\left(q_{t}-y^{n}\right)+\gamma \varepsilon_{z, t}(j)
$$

with $\gamma \geq 0$ a reduced-form parameter measuring the sensitivity of the frictionless optimal price with respect to idiosyncratic conditions.

Furthermore, firm $j$ observes only the signal $s_{\zeta, t}(j)$ :

$$
s_{\zeta, t}(j)=q_{t}+\varepsilon_{z, t}(j)+e_{\zeta, t}(j)
$$

with $e_{\zeta, t}(j)$ following a Gaussian white noise process with variance $\tilde{\sigma}_{\zeta^{\prime}}^{2}$ independent from $\varepsilon_{q, t}$ and $\varepsilon_{z, t}(j)$, and independently distributed across firms.

Suppose that a monetary expansion occurs. Given that idiosyncratic shocks are much more volatile than aggregate demand shocks, the resulting increase in firms' signals is mostly perceived as stemming from idiosyncratic conditions (and, to some extent, from the signal noise $e_{\zeta, t}(j)$ ). If $\gamma$ equals zero (i.e. if idiosyncratic conditions have no impact on firms' frictionless optimal prices), idiosyncratic shocks are nothing but noise and the distinction between $\varepsilon_{z, t}(j)$ and $e_{\zeta, t}(j)$ becomes meaningless. In this case, most of the rise in firms' signals is attributed to the noise, $\varepsilon_{z, t}(j)+e_{\zeta, t}(j)$. Prices are consequently raised very sluggishly, generating a large and persistent increase in aggregate output. Moreover, exactly as in Maćkowiak and Wiederholt's model, the larger the idiosyncratic shocks, the more sluggish the adjustment of prices. However, if $\gamma$ is positive, idiosyncratic shocks are no longer associated with noise. In this case, firms (imputing most of the increase in their signals to idiosyncratic conditions) swiftly raise their prices, causing only a small and transient increase in aggregate output. And the larger the idiosyncratic shocks, the stronger the price adjustment. As the title of Hellwig and Venkateswaran's paper suggests, therefore, firms set 'the right prices for the wrong reasons'.

Hellwig and Venkateswaran also consider a more complex case in which each firm observes more than one signal. The signals observed, however, do not enable firms to fully separate information about idiosyncratic conditions from information about aggregate demand. They show that the insights drawn from the simple case in terms of price adjustment and monetary non-neutrality extend to the more complex case.

The assumption of informational non-separability is certainly more appealing than the opposite one made by Maćkowiak and Wiederholt (2009). According to Hellwig and Venkateswaran, indeed, in the real world firms extract information essentially from their market activities (such as their sales or wage bill), but the information generated actually reflects variations in both idiosyncratic and aggregate conditions. Given that this assumption seems to considerably reduce the amount of monetary non-neutrality, Hellwig and Venkateswaran's results could represent a serious challenge to the models that assume informational separability.

At the same time, it is worth stressing that Maćkowiak and Wiederholt, in both of their 2009 and 2015 papers, develop extensions in which the assumption of independent signals is relaxed. In each case, they show that - exactly as in their baseline models - prices respond strongly to idiosyncratic shocks and weakly to aggregate demand shocks. ${ }^{15}$ The main reason, which is the key difference with Hellwig and Venkateswaran (2009), is that the precision of the signals received is still optimally chosen. In the extension proposed by Maćkowiak and Wiederholt (2015), for instance, firms can observe signals about the aggregate price level, total factor productivity, last period's sales, last period's wage bill, and relative wage rates. These variables are driven by multiple shocks, so that it is no longer the case that attending to idiosyncratic conditions and attending to aggregate conditions are independent activities. However, firms still optimally choose the precision of the signals 
received. The impulse responses turn out to be very similar to the baseline model. In particular, the real effects of monetary shocks are sizable and persistent.

Hence, as long as firms can choose optimal signals from a sufficiently rich menu, the separability assumption is less important for monetary non-neutrality than argued by Hellwig and Venkateswaran (2009). It remains to be seen whether or not informational separability really matters for the real effects of monetary shocks in more general set-ups.

\subsection{Single-good firms}

We have also seen that in Maćkowiak \& Wiederholt's, 2009 model, firms produce and set the price of only one good. This assumption is standard in the literature investigating the real effects of monetary shocks - and especially in DSGE models. However, the menu cost literature has recently argued (in the wake of Midrigan, 2011) that this assumption would actually have important implications for monetary non-neutrality. In particular, considering multi-product firms would allow to weaken the 'selection effect' which is inherent in state-dependent pricing models, and which explains why these models usually deliver much less monetary non-neutrality than their time-dependent counterparts. Alvarez and Lippi (2014) notably show that when the number of different goods priced by each firm tends to infinity, the selection effect vanishes and the amount of monetary non-neutrality generated by state-dependent models is as high as that generated by the popular model of Taylor (1980).

Pasten and Schoenle (2016) embed multi-product firms into Maćkowiak \& Wiederholt's, 2009 model. They assume that firms have to allocate their limited attention to track three types of disturbances: aggregate demand shocks, firm-specific shocks, and good-specific shocks (whose existence is documented by the authors). At first sight, it seems that a firm pricing a larger number of goods needs to spread thin its fixed amount of attention over a larger number of shocks. The attention allocated to track aggregate demand shocks is therefore mechanically reduced as the number of goods priced increases. As we have seen in Subsection 5.1, a lower amount of attention allocated to aggregate demand shocks turns into a lower signal-to-noise ratio $\tilde{s}_{q}$, implying larger and more persistent real effects of monetary shocks. However, Pasten and Schoenle show that this 'spread thin' effect is dominated by the existence of 'economies of scope in information processing'. These economies of scope stem from the fact that tracking aggregate-demand and firm-specific shocks, while requiring the same attention as tracking good-specific shocks, provides information that can be used to price all goods. The benefits of tracking aggregate-demand and firm-specific shocks thus scale up with the number of different goods priced, while the benefits of tracking good-specific shocks do not. Firms accordingly find it optimal to allocate more attention to aggregate demand shocks when they price more goods. The signal-to-noise ratio $\tilde{s}_{q}$ therefore increases with the number of goods priced, which implies - in sharp contrast to what happens in menu cost models - that the amount of monetary non-neutrality decreases with this number. ${ }^{16}$

Pasten and Schoenle find that the amount of monetary non-neutrality declines quite substantially with the number of goods priced: when firms price two goods, this amount is cut by three with respect to the single-good (i.e. Maćkowiak and Wiederholt's) case; when firms price eight goods or more, monetary shocks have almost no effect on aggregate output. Since there is strong evidence that, in the real world, both retailers and producers set the price of several goods, these results cast doubt on the ability of rational inattention models to generate large and persistent real effects from monetary shocks.

At the same time, Pasten and Schoenle's results critically rely on their baseline assumption that profit losses per good due to inattention remain constant as the number of goods varies. Among the two alternative assumptions they consider, one - namely that it is the shadow price of information capacity per good which is constant - implies that monetary non-neutrality is invariant to the number of goods firms price. They argue, however, that this latter assumption is much less plausible than the baseline one. Indeed, it creates a strong incentive for firms to split up their pricing decisions into single-good units (because profit losses per good now increase with the number of 
goods firms price), which is in sharp contrast with the data (where, as indicated above, most price setting units price several goods). ${ }^{17}$ Certainly, an interesting avenue for future research would be to empirically quantify the size of profit losses from inattention.

Two final points are worth emphasizing. First, even when money is nearly neutral, the attention allocated to aggregate demand shocks remains a relatively small portion of firms' total attention. For instance, even when firms price eight goods, they allocate no more than $23 \%$ of their attention to track aggregate demand shocks (as compared to $3 \%$ for the single-good case). This means that the amount of monetary non-neutrality is quite sensitive to the signal-to-noise ratio $\tilde{s}_{q}$. Secondly, strategic complementarities in price setting play an important role in Pasten and Schoenle's results. We have seen in Subsection 5.1 that in rational inattention models, strategic complementarities in price setting induce strategic complementarities in attention allocation. These latter are particularly strong in the multi-product firms model. To illustrate this strength, Pasten and Schoenle develop an extension of their baseline model where different firms price different numbers of goods. It turns out that in this economy with heterogeneous firms, the firms which price a single good allocate much more attention to aggregate demand shocks than they do in the baseline economy (with homogenous firms). Hence, the interaction with firms allocating more attention to aggregate demand shocks leads to more attention allocated to these shocks by firms that would have otherwise chosen to remain largely uninformed about them.

\section{Conclusion}

We have illustrated in this paper the renewed interest in Lucas's explanation of the non-neutrality of money put forward in his 1972 celebrated article - explanation based on information dispersion and signal extraction problems - by an increasing part of the literature investigating the real effects of monetary shocks. We have presented Woodford's contribution on imperfect common knowledge - the starting point of this renewal - and reviewed some important improvements suggested to overcome its main limitations. Among them, the rational inattention framework drawn up by Maćkowiak and Wiederholt stands out prominently. We have also stressed that some of the assumptions made by this line of research have been questioned by subsequent developments on the same track, thereby challenging its ability to replicate the large amount of monetary non-neutrality documented empirically and calling for additional work. Throughout the paper, we have tried to make as explicit as possible the relationship between these contributions and Lucas's own model.

Before concluding, it is interesting to note that while part of the profession rediscovers (or simply discovers) the merits of Lucas's, 1972 central argument, Lucas himself has turned his attention to another explanation of the non-neutrality of money: the existence of fixed costs of price adjustment - the so-called 'menu costs'. In a paper co-authored with Golosov (2007), indeed, Lucas proposes a menu cost model incorporating idiosyncratic shocks calibrated to match the large average size of price changes observed in the micro-price data. This model has now become the frame of reference in the menu cost literature dealing with monetary non-neutrality, setting the stage of what Klenow and Kryvtsov (2008) call 'second-generation state-dependent models'. ${ }^{18}$

\section{Notes}

1. De Vroey (2016) and Galbács (2020) provide two instances of a recent treatment and assessment of Lucas's contributions to macroeconomics.

2.

Keynes founded that subdiscipline, called macroeconomics, because he thought that it was impossible to explain the characteristics of business cycles within the discipline imposed by classical economic theory, a discipline imposed by its insistence on adherence to the two postulates (a) that markets be assumed to clear, and (b) that agents be assumed to act in their own self-interest. (Lucas \& Sargent, 1978, p. 58) 
3. Accordingly, we will not consider the literature on 'sticky information' that has developed in the wake of Mankiw and Reis (2002). In this body of work, agents update their information set only infrequently (and obtain full information when they do), but they have no signal extraction problem to solve.

4. The importance of higher-order expectations has been initially raised by Phelps (1983) and Townsend (1983), but not for the study of the non-neutrality of money.

5. An example of this conventional view is provided by Brzoza-Brzezina and Suda (2021) when they write: 'Over the last 25 years (or so) economists successfully brought various imperfections of the real world (be it departures from rationality or market imperfections) into the standard macroeconomic DSGE framework' although remaining 'certainly very far from having a complete "realistic" framework' (p. 231).

6. Equation (6) is actually the combination of firm $j$ 's log-linear approximation of the first-order condition, namely $p_{t}^{*}(j)=p_{t}+\xi\left(y_{t}-y^{n}\right)$, and the equation $q_{t}=p_{t}+y_{t}$.

7. To get Equation (10), first rewrite Equation (7) as $p_{t}(j)=(1-\xi) E_{j, t}^{(1)} p_{t}+\xi\left(E_{j, t}^{(1)} q_{t}-y^{n}\right)$. Then, iterating on this equation by repeatedly averaging across firms, gives Equation (10).

8. Several sources of strategic complementarities in price setting have been proposed, among which stand out decreasing returns to scale, firm-specific input markets, input-output linkages across sectors, and real wage rigidities at the aggregate level. See Woodford (2003b, Chapter 3) and Leahy (2011) for a thorough discussion on these sources.

9. Expectations of order zero correspond to the actual level of aggregate demand.

10. Firms, however, will never be certain that such a shock has occurred since they never know exactly the true value of aggregate demand.

11. This is because the denominator of $\tilde{s}_{q}$ (i.e., the variance $\tilde{\sigma}_{q}^{2}$ of the signal noise) is not pinned down by the model. By contrast, the parameter $\xi$ - which encapsulates the second source of persistence in Woodford's framework is a reduced-form parameter determined by the structural parameters of the model.

12. In their baseline model, Maćkowiak and Wiederholt assume that firms choose the optimal values of $\kappa_{q}$ and $\kappa_{z}$ once and for all, in period $t=0$.

13. Angeletos and La'O also assume that: (i) firms set prices according to Calvo (1983) pricing model; (ii) the level of aggregate demand in a given period can be perfectly observed at the beginning of the following period (as in Lucas's model). The mechanism described in the text, however, does not rely on any of these two assumptions. It relies on the heterogeneity not only of updating information received by each agent but also of the agents' beliefs about the characteristics of the information received by other agents.

14. For instance, Christiano et al. (2005) report that aggregate output reaches its peak response about one year after having started to react to a positive monetary shock.

15. Hellwig and Venkateswaran are aware of the extension in Maćkowiak and Wiederholt (2009), but argue that this latter is quite specific (Hellwig \& Venkateswaran, 2009, p. 59, n. 2, and p. 74, n. 20).

16. Pasten and Schoenle nevertheless make it clear that the allocation of attention, as well as the resulting amount of monetary non-neutrality, is independent from the number of goods firms price when those goods are not subject to shocks (or when good-specific shocks have no impact on firms' profits). Hence, what ultimately matters is the number of shocks that do require paying attention to, not the number of goods per se.

17. Pasten and Schoenle also stress that this alternative assumption would mean that the marginal cost of expanding information capacity is higher for firms that price more goods. In their eyes, 'This is a priori implausible: It implies, for example, that buying software to support the pricing process is more expansive if firms decide more prices (or if their total sales are larger)' (Pasten \& Schoenle, 2016, p. 8, brackets in the original).

18. In this perspective, it is also interesting to note the recent emergence of models in which an optimal signal choice problem either complements (e.g. Yang, 2021) or substitutes for (e.g. Matějka, 2016; Stevens, 2020) a menu cost.

\section{Disclosure statement}

No potential conflict of interest was reported by the author(s).

\section{Notes on contributors}

Pierrick Clerc is a Associate Professor at HEC Liège.

Rodolphe Dos Santos Ferreira is a Professor Emeritus at the University of Strasbourg.

\section{ORCID}

Pierrick Clerc (D) http://orcid.org/0000-0002-5854-4276

Rodolphe Dos Santos Ferreira (D) http://orcid.org/0000-0001-6966-281X 


\section{References}

Altig, D., Christiano, L. J., \& Eichenbaum, M. (2011). Firm-specific capital, nominal rigidities and the business cycle. Review of Economic Dynamics, 14(2), 225-247. https://doi.org/10.1016/j.red.2010.01.001

Alvarez, F., \& Lippi, F. (2014). Price setting with menu cost for multiproduct firms. Econometrica, 82(1), 89-135. https:// doi.org/10.3982/ECTA10662

Angeletos, G.-M., \& La'O, J. (2009). Incomplete information, higher-order beliefs and price inertia. Journal of Monetary Economics, 56, S19-S37. https://doi.org/10.1016/j.jmoneco.2009.07.001

Barro, R., \& Grossman, H. (1971). A general disequilibrium model of income and employment. American Economic Review, 61(1), 82-93.

Brzoza-Brzezina, M., \& Suda, J. (2021). Are DSGE models irreparably flawed? Bank i Kredyt, 52(3), $227-252$.

Calvo, G. (1983). Staggered prices in a utility-maximizing framework. Journal of Monetary Economics, 12(3), 383-398. https://doi.org/10.1016/0304-3932(83)90060-0

Christiano, L. J., Eichenbaum, M., \& Evans, C. L. (2005). Nominal rigidities and the dynamic effects of a shock to monetary policy. Journal of Political Economy, 113(1), 1-45. https://doi.org/10.1086/426038

De Vroey, M. (2016). A history of macroeconomics from Keynes to Lucas and beyond. Cambridge University Press.

Friedman, M., \& Schwartz, A. J. (1963). A monetary history of the United States, 1867-1960. Princeton University Press.

Galbács, P. (2020). The Friedman-Lucas transition in macroeconomics: A sructuralist approach. Academic Press.

Golosov, M., \& Lucas, R. E., Jr. (2007). Menu costs and Phillips curves. Journal of Political Economy, 115(2), $171-199$. https://doi.org/10.1086/512625

Hellwig, C., \& Venkateswaran, V. (2009). Setting the right prices for the wrong reasons. Journal of Monetary Economics, 56, S57-S77. https://doi.org/10.1016/j.jmoneco.2009.06.013

Klenow, P. J., \& Kryvtsov, O. (2008). State-dependent or time-dependent pricing: Does it matter for recent U.S. Inflation? Quarterly Journal of Economics, 123(3), 863-904. https://doi.org/10.1162/qjec.2008.123.3.863

Kydland, F. E., \& Prescott, E. C. (1982). Time to build and aggregate fluctuations. Econometrica, 50(6), 1345-1370. https:// doi.org/10.2307/1913386

Leahy, J. (2011). A survey of New Keynesian theories of aggregate supply and their relation to industrial organization. Journal of Money, Credit and Banking, 43(Supplement), 87-110. https://doi.org/10.1111/j.1538-4616.2011.00411.x

Lucas, R. E., Jr. (1972). Expectations and the neutrality of money. Journal of Economic Theory, 4(2), 103-124. https://doi. org/10.1016/0022-0531(72)90142-1

Lucas, R. E., Jr. (1975). An equilibrium model of the business cycle. Journal of Political Economy, 83(6), 1113-1144. https:// doi.org/10.1086/260386

Lucas, R. E., Jr., \& Sargent, T. J. (1978, June 18). After Keynesian macroeconomics. In After the Phillips curve: Persistence of high inflation and high unemployment, Proceedings of a conference, Edgartown, MA (pp. 49-72). Federal Reserve Bank of Boston.

Maćkowiak, B., \& Wiederholt, M. (2009). Optimal sticky prices under rational inattention. American Economic Review, 99 (3), 769-803. https://doi.org/10.1257/aer.99.3.769

Maćkowiak, B., \& Wiederholt, M. (2015). Business cycle dynamics under rational inattention. The Review of Economic Studies, 82(4), 1502-1532. https://doi.org/10.1093/restud/rdv027

Mankiw, N. G., \& Reis, R. (2002). Sticky information versus sticky prices: A proposal to replace the New Keynesian Phillips curve. The Quarterly Journal of Economics, 117(4), 1295-1328. https://doi.org/10.1162/003355302320935034

Matějka, F. (2016). Rationally inattentive seller: Sales and discrete pricing. The Review of Economic Studies, 83(3), 11251155. https://doi.org/10.1093/restud/rdv049

Midrigan, V. (2011). Menu costs, multiproduct firms, and aggregate fluctuations. Econometrica, 79(4), 1139-1180. https://doi.org/10.3982/ECTA6735

Muth, J. F. (1961). Rational expectations and the theory of price movements. Econometrica, 29(3), 315-335. https://doi. org/10.2307/1909635

Pasten, E., \& Schoenle, R. (2016). Rational inattention, multi-product firms and the neutrality of money. Journal of Monetary Economics, 80(1), 1-16. https://doi.org/10.1016/j.jmoneco.2016.04.004

Phelps, E. S. (1969). The new microeconomics in inflation and employment theory. American Economic Review: Papers and Proceedings, 59(2), 147-160.

Phelps, E. S. (1970). Microeconomic foundations of employment and inflation theory. W.W. Norton.

Phelps, E. S. (1983). The trouble with rational expectations and the problem of inflation stabilization. In R. Frydman \& E. S. Phelps (Eds.), Individual forecasting and aggregate outcomes: 'Rational expectations' examined (pp. 31-41). Cambridge University Press.

Sims, C. A. (1998). Stickiness. Carnegie-Rochester Conference Series on Public Policy, 49, 317-356. https://doi.org/10.1016/ S0167-2231(99)00013-5

Sims, C. A. (2003). Implications of rational inattention. Journal of Monetary Economics, 50(3), 665-690. https://doi.org/10. 1016/S0304-3932(03)00029-1

Stevens, L. (2020). Coarse pricing policies. Review of Economic Studies, 87(1), 420-453. https://doi.org/10.1093/restud/ rdz036 
Taylor, J. B. (1980). Aggregate dynamics and staggered contracts. Journal of Political Economy, 88(1), 1-23. https://doi. org/10.1086/260845

Townsend, R. M. (1983). Forecasting the forecasts of others. Journal of Political Economy, 91(4), 546-588. https://doi.org/ $10.1086 / 261166$

Woodford, M. (2003a). Imperfect common knowledge and the effects of monetary policy. In P. Aghion, R. Frydman, J. Stiglitz, \& M. Woodford (Eds.), Knowledge, information, and expectations in modern macroeconomics: In honor of Edmund S. Phelps (pp. 25-58). Princeton University Press.

Woodford, M. (2003b). Interest and prices: Foundations of a theory of monetary policy. Princeton University Press.

Yang, C. (2021). Rational inattention, menu costs, and multi-product firms: Micro evidence and aggregate implications. Mimeo. 